\title{
Titration of serum p53 antibodies in patients with gastric cancer: a single-institute study of $\mathbf{4 0}$ patients
}

\author{
Keiji Shimizu, Yuji Ueda, and HisaKazu Yamagishi \\ Department of Surgery, Division of Digestive Surgery, Kyoto Prefectural University of Medicine, 465 Kajii-cho, Kawaramachi-dori Hirokoji, \\ Kamigyo-ku, Kyoto 602-8566, Japan
}

\begin{abstract}
Background. Alterations of the p53 tumor suppressor gene are the most commonly observed genetic abnormalities in many different types of human malignancies. The accumulation of mutant p53 often leads to the production of p53 antibody (p53-Ab) in the sera of patients with various cancers. To evaluate the clinical implications of serum p53-Abs in patients with gastric cancer, we compared p53-Abs with conventional tumor markers such as carcinoembryonic antigen (CEA) and carbohydrate antigen (CA)19-9.

Methods. Serum samples were obtained preoperatively from 40 patients with histologically confirmed gastric adenocarcinoma, including 28 (70\%) patients in stage Ia. The serum p53Abs were assessed by enzyme-linked immunosorbent assay, using a new version of a highly specific, quantitative p53-Abs Kit (MESACUP Kit II).

Results. p53-Abs were detected in $6(15 \%)$ of 40 patients with gastric cancer, including 3 patients with early gastric cancer. Seven $(\mathbf{1 7 . 5} \%)$ of the $\mathbf{4 0}$ patients were positive for CEA in serum. However, none of 7 patients with high CEA levels were positive for p53-Abs. No significant correlation of p53Abs with patient age, sex, pathological parameters, tumor markers such as CEA and CA19-9, or poor survival ( $P=$ 0.116) was observed.

Conclusion. Although we employed the latest version of the p53-Abs Kit, the sensitivity of serum p53-Ab in gastric cancer patients was relatively low. No correlation was found between the presence of $\mathbf{p 5 3}-\mathrm{Ab}$ and the staging of cancer or survival. However, serum p53-Ab was detectable in patients with gastric cancer even in the early stages of disease. In addition, it may be independent of CEA and CA19-9.
\end{abstract}

Key words Gastric cancer · p53 Antibody · Tumor marker

Offprint requests to: $\mathrm{Y}$. Ueda

Received: April 12, 2005 / Accepted: May 19, 2005

\section{Introduction}

Conventional tumor markers such as carcinoembryonic antigen (CEA), carbohydrate antigen (CA)19-9, squamous cell carcinoma antigen ( $\mathrm{SCC}-\mathrm{Ag}$ ), tissue polypeptide antigen (TPA), and cytokeratin fragment (CYFRA)21-1, are not suitable for the screening or monitoring of patients with malignant tumors, because of low sensitivity and specificity. It has been suggested that oncogenes and tumor suppressor genes and their products may be useful in biochemical tests for cancer [1]. The tumor suppressor $p 53$ gene, located on chromosome $17 \mathrm{p} 13.1$, frequently undergoes mutation in the genesis of human cancer [2]. The frequency of $p 53$ mutations in all malignant tumors was reported to be at least $50 \%[3,4]$. The mutated $p 53$ gene leads to the synthesis of a mutant protein with a longer than normal half-life, and massive overexpression of the protein products $[5,6]$. The accumulation of mutant $\mathrm{p} 53$ protein has been found to be immunogenic in cancer patients and to result in the production of p53 antibody (p53$\mathrm{Ab})$ in serum [7].

The p53-Ab in the sera of cancer patients can be detected by immunoprecipitation or Western blotting, or by enzyme-linked immunosorbent assay (ELISA) [7-10]. Circulating p53-Abs in patients have been reported for various types of carcinomas $[9,10]$, including breast cancer, hematopoietic malignancy, esophageal cancer, colon cancer, ovarian cancer, lung cancer, pancreatic cancer, and gastric cancer [11-15]. Several studies have demonstrated that the p53-Ab in sera served as an early marker of malignant disease, as an indicator for monitoring patients with malignant tumors during treatment, and as a prognostic factor for patients with several types of tumors [11, 16-18]. Because these studies attempted to evaluate the clinical value of p53-Ab under different conditions, the role of $\mathrm{p} 53-\mathrm{Ab}$ in patients with malignant tumors has not been clearly established yet. 
Gastric cancer is widely prevalent in the world and is one of the leading malignancies in terms of incidence and cause of cancer death in East Asia and South America. In Japan, the mortality rate of gastric cancer is showing a decreasing trend, reflecting advances in medical technology, such as early detection and treatment with an endoscope. It is necessary to evaluate the clinical usefulness of new early diagnostic markers of malignancies (for example, in gastric cancer) which could be found in the early stage of tumorigenesis. In this regard, reports on $\mathrm{p} 53-\mathrm{Ab}$ in the sera of patients with gastric cancer have not been adequate [15, 19-22].

In this study, we examined 40 patients with gastric cancer, including $28(70 \%)$ patients in the early stages of the disease, for the presence of circulating antibodies against the tumor suppressor protein p53 and we examined these findings in relation to conventional tumor markers, tumor characteristics, and the clinical status of the patients. The serum levels of p53-Abs were assessed by ELISA, using a new version of a highly specific, quantitative p53-Ab Kit [23].

\section{Patients and methods}

\section{Patients}

Forty patients with primary gastric cancer who underwent gastric resection at the Department of Surgery, Division of Digestive Surgery, Kyoto Prefectural University of Medicine, Kyoto, Japan, between July and December 2000 were enrolled in this study. Written informed consent was obtained from each patient. No patients had received preoperative radiotherapy or chemotherapy. There were $28(70 \%)$ male and $12(30 \%)$ female patients, with an average age of 60.6 years (range, 28-86 years).

\section{Serum and tumor samples}

Serum samples were collected from each patient before and 28 days after surgery. Samples were stored at $-80^{\circ} \mathrm{C}$ until they were assayed. After resection, the tumor specimens were subjected to routine processing for the control of resection margins; also, exact histological investigation included an evaluation of staging in accordance with the International Union Against Cancer (UICC)/TNM classification.

\section{Enzyme immunoassay for serum p53 antibodies}

Serum p53-Ab levels were assessed by (ELISA) with the anti-p53 EIA Kit II (MESACUP anti-p53 Test; Medical and Biological Laboratories (MBL), Nagoya, Japan). In brief, the samples were added, for $1 \mathrm{~h}$ at $37^{\circ} \mathrm{C}$, to microtiter wells coated with wild-type human p53 protein or a control protein to detect nonspecific interactions. After washing, a peroxidase-conjugated goat antihuman immunoglobulin $\mathrm{G}$ that binds p53-Ab was applied for $1 \mathrm{~h}$ at $37^{\circ} \mathrm{C}$. Then substrate solution was added for $30 \mathrm{~min}$ at $37^{\circ} \mathrm{C}$. After the addition of stop solution, color development was assessed by measuring absorption at $450 \mathrm{~nm}$, using a photospectrometer. Levels of p53-Abs were determined from a calibration curve constructed from the specific signals of standards. The cutoff value for serum p53-Abs was $1.3 \mathrm{U} / \mathrm{ml}$. The specificity of this assay is greater than $95.5 \%$ [23].

\section{CEA and CA19-9 assays}

Serum CEA concentrations were measured with an immunoradiometric assay, using a CEA RIABEAD Kit (Abbott Japan, Tokyo, Japan). Serum CA19-9 concentrations were also measured with an immunoradiometric assay, using a CA19-9 RIA Kit (TFB, Tokyo, Japan). According to the manufacturers, the cutoff values for serum CEA and CA19-9 were $2.5 \mathrm{ng} / \mathrm{ml}$ and $37 \mathrm{U} / \mathrm{ml}$, respectively.

\section{Statistical analysis}

Fisher's exact test, Student's $t$-test, and the MannWhitney $U$-test were used to determine the significance of differences between two groups. Survival curves were plotted using the Kaplan-Meier method. The logrank test was adopted to compare two groups. Cox regression analysis was performed to determine which factors would be useful in predicting overall survival. A $P$ value of less than 0.05 was considered significant.

\section{Results}

\section{Detection of serum p53 antibody in gastric cancer}

We tested serum samples from 40 patients with gastric cancer for the presence of p53-Abs. Six $(15.0 \%)$ of the 40 patients were positive for serum p53-Abs: the mean age of this group was 63 years (range, 40-77 years), and the male/female ratio was $2: 1$. The other $34(85.0 \%)$ patients were negative for serum p53-Abs: their mean age was 60.2 years (range, 28-86 years), and the male/ female ratio was $2.4: 1$. Based on the UICC/TNM classification, 3 of the 6 p53Ab-positive patients were in stage Ia; none of the 6 patients was in stage IV, but p53Abs were also detected at stages II, IIIa, and IIIb. No significant differences between the p53Ab-positive and -negative groups were observed in age, sex, or tumor staging (Table 1).

We analyzed the histopathological factors of tissue type, tumor invasion, lymph node metastasis, and dis- 
Table 1. Correlation between the presence of serum p53 antibody $(\mathrm{Ab})$ and clinicopathological features in gastric cancer

\begin{tabular}{lcccc}
\hline & \multicolumn{4}{c}{$\begin{array}{c}\text { Serum p53 } \\
\text { antibody }\end{array}$} \\
\cline { 3 - 4 } Variables & Total & Positive & Negative & $P$ value \\
\hline Number of patients & 40 & 6 & 34 & \\
Age (years) & 60.6 & 63 & 60.2 & 0.64 \\
Sex (M:F) & $2.3: 1$ & $2.0: 1$ & $2.4: 1$ & 0.88 \\
Stage & & & & \\
$\quad$ Ia & 28 & 3 & 25 & \\
Ib & 3 & 0 & 3 & 0.3 \\
II & 4 & 1 & 3 & \\
IIIa & 1 & 1 & 0 & \\
IIIb & 2 & 1 & 1 & \\
IV & 2 & 0 & 2 & \\
& & & & \\
& & & &
\end{tabular}

Table 2. Correlation between the presence of serum p53-Ab and histopathological findings in gastric cancer

\begin{tabular}{lccc}
\hline & \multicolumn{2}{c}{ Serum p53 antibody } & \\
\cline { 2 - 3 } & Positive & Negative & $P$ value \\
\hline Tissue type & 2 & 21 & 0.272 \\
$\quad$ Differentiated & 4 & 13 & \\
$\quad$ Undifferentiated & 3 & 25 & 0.363 \\
Tumor invasion & 3 & 9 & \\
$\quad$ Mucosa or submucosa & & & \\
$\quad$ Deeper than submucosa & 3 & 31 & 0.111 \\
Lymph node metastasis & 3 & 3 & \\
$\quad$ Negative & & & \\
$\quad$ Positive & 6 & 33 & 0.909 \\
Distant metastasis & 0 & 1 & \\
$\quad$ Negative & & & \\
$\quad$ Positive & & &
\end{tabular}

tant metastasis. Four (66.7\%) of the 6 p53Ab-positive patients had histologically undifferentiated adenocarcinomas, compared to $13(38.2 \%)$ of the 34 p53Abnegative patients $(P=0.272)$. Three $(50 \%)$ of the 6 patients with lymph node metastasis were positive for serum $\mathrm{p} 53-\mathrm{Ab}$, whereas only $3(8.8 \%)$ of the 34 patients without lymph node metastasis were positive $(P=$ 0.111). There were no significant differences in these factors between the groups who were positive and negative for p53-Ab (Table 2).

\section{Sensitivity of serum CEA, CA19-9, and p53 antibody in gastric cancer}

The correlation between the presence of serum $\mathrm{p} 53-\mathrm{Ab}$ and the two tumor markers CEA and CA19-9 was analyzed. The sensitivities of CEA and CA19-9 in this study were $17.5 \%$ (7/40) and 10\% (4/40), respectively. The 7
Table 3. Correlation between the presence of serum p53-Ab and tumor markers in gastric cancer

\begin{tabular}{lccc} 
& \multicolumn{2}{c}{ Serum p53 antibody } & \\
\cline { 2 - 3 } & Positive & Negative & $P$ value \\
\hline CEA & & & \\
Positive & 0 & 7 & 0.426 \\
Negative & 6 & 27 & \\
CA19-9 & 1 & 3 & 0.762 \\
Positive & 5 & 31 & \\
Negative & 5 & & \\
\hline
\end{tabular}

patients positive for CEA did not express p53-Abs, and CEA was not detected in any p53-Ab-positive patients (Table 3).

We analyzed the sensitivity of serum p53-Ab and CEA according to stage based on the UICC/TNM classification. Three $(10.7 \%)$ of the 28 patients in stage Ia were positive for serum $\mathrm{p} 53-\mathrm{Ab}$, whereas none $(0 \%)$ of these 28 patients was positive for CEA. In stage IV, both patients were positive for CEA, but neither was positive for $\mathrm{p} 53-\mathrm{Ab}$ (Table 4$)$.

Three $(50 \%)$ of the 6 p53Ab-positive patients became negative postoperatively, while $5(71.4 \%)$ of the 7 CEA-positive patients became negative postoperatively (Table 4).

\section{Detection of serum p53 antibody in stage Ia gastric cancer}

We focused on the stage-Ia patients to investigate the clinical usefulness of the levels of serum $\mathrm{p} 53-\mathrm{Ab}$ as a marker for the early detection of gastric cancer. Table 5 demonstrates that only p53-Ab was positive in patients with stage Ia gastric cancer, whereas CEA and CA19-9 were not positive. No significant differences between the p53Ab-positive and -negative groups were observed in regard to tissue type or tumor invasion.

\section{Survival rates}

The 4-year survival rates for patients with sera that was positive or negative for CEA, CA19-9, and p53-Ab are shown in Table 6. The median follow-up time for all 40 patients was 31.7 months (range, 1-48 months). The 4year survival rate was $82.9 \%$ for the p53Ab-negative patients and $60 \%$ for the p53-Ab-positive patients. However, there was no significant difference in the rate of survival between the p53-Ab-positive group and the p53Ab-negative group $(P=0.116)$. In contrast, the overall survival of patients positive for CEA was significantly shorter than that in the CEA-negative patients $(P$ $=0.0008)$ (Table 6). 
Table 4. Correlations between sensitivity of serum CEA and p53 Ab according to clinical stage

\begin{tabular}{lcrc}
\hline & Serum p53 antibody & CEA & $P$ value \\
\hline Stage & & & \\
Ia & $10.7 \%(3 / 28)$ & $0 \%(0 / 28)$ & 0.49 \\
Ib & $0 \%(0 / 3)$ & $66.7 \%(2 / 3)$ & 0.19 \\
II & $25 \%(1 / 4)$ & $50 \%(2 / 4)$ & 0.56 \\
IIIa & $100 \%(1 / 1)$ & $0 \%(0 / 1)$ & 0.31 \\
IIIb & $50 \%(1 / 2)$ & $50 \%(1 / 2)$ & 1 \\
IV & $0 \%(0 / 2)$ & $100 \%(2 / 2)$ & 0.12 \\
Negative conversion & $50 \%(3 / 6)$ & $71.4 \%(5 / 7)$ & 0.52 \\
$\quad$ post-surgery & & & \\
\hline
\end{tabular}

Table 5. Correlation between the presence of serum p53-Ab, histopathological findings, and tumor markers in stage Ia patients

\begin{tabular}{lccc}
\hline & \multicolumn{2}{c}{ Serum p53 antibody } & \\
\cline { 2 - 3 } & Positive & Negative & $P$ value \\
\hline Tissue type & & & \\
$\quad$ Differentiated & 2 & 19 & 0.853 \\
$\quad$ Undifferentiated & 1 & 6 & \\
Tumor invasion & & & \\
$\quad$ Mucosa & 2 & 15 & 0.906 \\
$\quad$ Submucosa & 1 & 10 & \\
CEA & 0 & 0 & 0.49 \\
$\quad$ Positive & 3 & 25 & \\
$\quad$ Negative & & & 0.49 \\
CA19-9 & 0 & 0 & \\
$\quad$ Positive & 3 & 25 & \\
Negative & & & \\
\hline
\end{tabular}

However, Cox regression analysis of all factors listed in Tables 1 and 2 revealed that lymph node metastasis, but not $\mathrm{p} 53 \mathrm{Ab}$ or CEA, was an independent prognostic factor in gastric cancer $(P<0.05)$.

\section{Discussion}

At present, there is no satisfactory tumor marker for the diagnosis or monitoring of malignant disease. It is expected that a new biological marker which shows high sensitivity and specificity and can be used with relative ease will be established.

$\mathrm{p} 53-\mathrm{Ab}$ is an autoantibody induced by mutation of the $p 53$ tumor suppressor gene, and has been detected in the sera of patients with various types of cancers. Since its initial description more than 20 years ago, the usefulness of serum $\mathrm{p} 53-\mathrm{Ab}$ in patients with various cancers has been reported [9-15]. Gastric cancer remains a major cause of cancer-related deaths in the world. Serum CEA is generally used for the diagnosis
Table 6. Association between 4-year survival rates and tumor markers in patients with gastric cancer

\begin{tabular}{lcc}
\hline & Survival rate $(\%)$ & $P$ value \\
\hline CEA & & \\
Positive & 25.7 & 0.0008 \\
Negative & 92.3 & \\
CA19-9 & & 0.118 \\
Positive & 50 & \\
Negative & 85.4 & 0.116 \\
p53-Ab & & \\
Positive & 60 & \\
Negative & 82.9 & \\
\hline
\end{tabular}

and monitoring of gastric cancer, but only a limited proportion of patients benefit. Therefore, potential new biological markers, such as p53-Ab, E-cadherin, or hepatocyte growth factor (HGF) for patients with gastric cancer, have received attention [24-26]. Because gastric cancer can be diagnosed at an early stage by endoscopy, it is suitable for testing a potential biological marker for early diagnosis. Nevertheless, only a small number of reports regarding the evaluation of p53-Abs in the sera of patients with gastric cancer have been published to date [15, 19-22].

The present study demonstrated that, in $15 \%$ (6 of 40) of patients, gastric cancer was detectable by p53-Ab ELISA assay preoperatively. This is comparable with previous observations in patients with gastric cancer [15, 19-23]. No significant correlation between p53-Abs and either tumor stage, tissue grade of differentiation, depth of tumor invasion, lymph node metastasis, or distant metastasis was observed. The positive rate for CEA and CA19-9 in the sera of patients with gastric cancer was $17.5 \%$ (7 of 40 ) and $10 \%$ (4 of 40 ), respectively, which is similar to results reported by other groups [27, 28]. Most interestingly, the 6 patients positive for p53Abs did not show high levels of CEA, and only 1 patient positive for p53-Ab showed a high CA19-9 level. The presence of $\mathrm{p} 53-\mathrm{Ab}$ was not associated with serum CEA 
or CA19-9 ( $P=0.426$ and $P=0.762$, respectively). It was supposed that p53-Ab might be an independent marker of CEA or CA19-9. The positivity rate for the diagnosis of gastric cancer increased to $32.5 \%$ when p53-Ab and CEA were combined in this study.

Because alterations in the $p 53$ gene result in an accumulation of the protein in tumor cells, the presence of serum $\mathrm{p} 53-\mathrm{Ab}$ was described as an early event that could predate the diagnosis [29]. Our results demonstrated that, of 28 patients with stage Ia gastric cancer tested preoperatively, 3 were positive for p53-Ab in serum, whereas none was positive for serum CEA or CA19-9. A p53 mutation may be not only an advancedstage phenomenon but may also be an early event of carcinogenesis. Several studies have reported that p53$\mathrm{Ab}$ can be found in the serum of individuals at high risk of developing cancer, including heavy smokers and workers exposed to vinyl chloride $[16,29,30]$. In contrast, no association between p53 abnormalities (overexpression/mutation) and Helicobacter pylori infection was found in patients with gastric adenocarcinoma; therefore, mutations of the $p 53$ gene do not seem to be a predominant event in gastric carcinogenesis [31]. These contradictory findings might be explained by a report that $39.1 \%$ of patients with gastric cancer positive for $\mathrm{p} 53-\mathrm{Ab}$ in sera had tumor tissues that stained negative for $\mathrm{p} 53$ protein [19].

Although there have been several reports that the presence of $\mathrm{p} 53-\mathrm{Ab}$ in serum was a prognostic factor for patients with various types of malignancies, the prognostic value of p53-Abs in patients with gastric cancer is still controversial $[15,19,21]$. We did not find a significant correlation between the presence of $\mathrm{p} 53$-Abs in the sera of patients with gastric cancer and overall survival, despite the finding that the 4-year survival rate was about $20 \%$ higher in the p53-Ab-negative patients than that in the -positive patients. On the other hand, high levels of CEA could be associated with prognosis. However, Cox regression analysis revealed that lymph node metastasis, but not p53 Ab or CEA, served as an independent prognostic factor in gastric cancer in this series.

The $\mathrm{p} 53$-Abs circulating in patients with various types of cancer can be detected by several methods, including immunoprecipitation, Western blotting, and ELISA [710]. Because none of these methods give satisfactory rates of detection, further improvement is needed. We employed the latest version of an ELISA kit, which has the advantage of quantitative analysis, for the detection of p53-Ab. Using this assay, Shimada et al. [23], in a multiinstitutional study, reported $20.4 \%$ positivity for p53-Abs in 1085 patients with 15 types of malignant tumors, and they determined a cutoff value of $1.3 \mathrm{U} / \mathrm{ml}$ with over $95.5 \%$ specificity by analyzing serum samples of 205 healthy controls. This assay could thus contribute to achieving high true-positive rates with low false- positive rates. Recently, a new protocol for the rapid and sensitive detection of p53-Abs in serum by immunomagnetic electrochemiluminescence (IM-ECL) was developed [32]. Further study will be needed to fully elucidate the importance of this detection method.

Here, we measured circulating p53-Ab levels in the sera of 40 patients with gastric cancer using a new version of the p53-Abs ELISA kit. The presence of p53-Ab was demonstrated in 15\% (6 of 40) of the patients with gastric cancer preoperatively. No correlation was found between the presence of $\mathrm{p} 53-\mathrm{Ab}$ and the staging of cancer or survival. However, circulating p53-Ab was detectable in patients with early-stage gastric cancer, and was independent of the currently available tumor markers CEA and CA19-9.

Acknowledgments This work was part of a multiinstitutional analysis by the Japan p53 Antibody Research Group, conducted by Drs. H. Shimada and T. Ochiai (Chiba University Graduate School of Medicine).

\section{References}

1. Diamandis EP. Oncogenes and tumor suppressor genes: new biochemical tests. Crit Rev Clin Lab Sci 1992;29:269-305.

2. Levine A, Momand J, Finlay C. The p53 tumor suppressor gene. Nature 1991;351:453-5.

3. Soussi T, Legros Y, Lubin R, Ory K, Schlichtholz B. Multifactorial analysis of p53 alteration in human cancer: a review. Int $\mathrm{J}$ Cancer 1994;57:1-9.

4. Chang F, Syrjanen S, Syrjanen K. Implications of the $p 53$ tumor suppressor gene in clinical oncology. J Clin Oncol 1995;13:100922.

5. Lane D, Benchimol S. p53: oncogene or anti-oncogene? Genes Dev 1990;4:1-8.

6. Davidoff A, Humphrey P, Iglehart J, Marks J. Genetic basis for p53 overexpression in human breast cancer. Proc Natl Acad Sci USA 1991;88:5006-10.

7. Crawford LV, Pim DC, Bulbrook RD. Detection of antibodies against the cellular protein $\mathrm{p} 53$ in sera from patients with breast cancer. Int J Cancer 1982;30:403-8.

8. Caron FC, May LF, Mouriesse H, Lemerle J, Chandrasekaran K, May P. Presence of circulating antibodies against cellular protein p53 in a notable proportion of children with B-cell lymphoma. Int J Cancer 1987;39:185-9.

9. Angelopoulou K, Diamandis EP, Sutherland DJA, Kellen JA, Bunting PS. Prevalence of serum antibodies against the p53 tumor suppressor gene protein in various cancers. Int J Cancer 1994;58:480-7.

10. Lubin R, Schlichtholz B, Teillaud JL, Garay E, Bussel A, Wild C, et al. p53 antibodies in patients with various types of cancer: assay, identification and characterization. Clin Cancer Res 1995;1:14639.

11. Peyrat JP, Bonneterre J, Lubin R, Vanlemmens L, Fournier J, Soussi T. Prognostic significance of circulating p53 antibodies in patients undergoing surgery for locoregional breast cancer. Lancet 1995;345:621-2.

12. Lethinen T, Luostarinen T, Dillner J. Serum p53 accumulation and altered antibody response to Epstein-Barr virus proteins precede diagnosis of haemopoietic malignancies of lymphoid origin. Br J Haematol 1996;93:104-10. 
13. Breveren von MC, Hollstein MC, Cawley HM, De Benedetti VGM, Bennett WP, Liang L, et al. Circulating anti-p53 antibodies in oesophageal cancer patients are found predominantly in individuals with p53 core domain mutations in their tumors. Cancer Res 1996;56:4917-21.

14. Marxsen J, Schmiegel W, Roder C, Harder R, Juhl H, HenneBruns D, et al. Detection of the anti-p53 antibody response in malignant and benign pancreatic disease. Br J Cancer 1994;70: 1031-4.

15. Nakajima K, Suzuki T, Shimada H, Hayashi H, Takeda A, Ochiai $\mathrm{T}$. Detection of preoperative serum anti-p53 antibodies in gastric cancer. Tumor Biol 1999;20;147-52.

16. Trivers GE, Cawley HL, DeBenedetti VM, Hollstein M, Marion MJ, Bennett WP, et al. Anti-p53 antibodies in sera of workers occupationally exposed to vinyl chloride. J Natl Cancer Inst 1995;87:1400-7.

17. Hammel P, Boissier B, Chaumette MT, Piedbois P, Rotman N, Kouyoumdjian JC, et al. Detection and monitoring of serum p53 antibodies in patients with colorectal cancer. Gut 1997;40:356-61.

18. Houbiers JG, van der Burg SH, van de Watering LM, Tollenaar RA, Brand A, van de Velde CJ, et al. Antibodies against p53 are associated with poor prognosis of colorectal cancer. Br J Cancer 1995;72:637-41.

19. Maehara Y, Kakeji Y, Watanabe A, Baba H, Kusumoto H, Kohnoe S, et al. Clinical implications of serum anti-p53 antibodies for patients with gastric carcinoma. Cancer 1999;85:302-8.

20. Würl P, Weigmann F, Meye A, Fittkau M, Rose U, Berger D, et al. Detection of p53 autoantibodies in sera of gastric cancer patients and their prognostic relevance. Scand J Gastroenterol 1997;32:1147-51.

21. Wu CW, Lin YY, Chen GD, Chi CW, Carbone DP, Chen JY. Serum anti-p53 antibodies in gastric adenocarcinoma patients are associated with poor prognosis, lymph node metastasis and poorly differentiated nuclear grade. Br J Cancer 1999;80:483-8.

22. Shiota G, Ishida M, Noguchi N, Takano Y, Oyama K, Okubo M, et al. Clinical significance of serum p53 antibody in patients with gastric cancer. Res Commun Mol Pathol Pharmacol 1998;99:4151.
23. Shimada H, Ochiai T, Nomura F. Titration of serum p53 antibodies in 1085 patients with various types of malignant tumors. Cancer 2003;97:682-9.

24. Chan AO, Chu KM, Lam SK, Wong BC, Kwok KF, Law S, et al. Soluble E-cadherin is an independent pretherapeutic factor for long-term survival in gastric cancer. J Clin Oncol 2003;21:228893.

25. Juhasz M, Ebert MP, Schulz HU, Rocken C, Molnar B, Tulassay $\mathrm{Z}$, et al. Dual role of serum soluble E-cadherin as a biological marker of metastatic development in gastric cancer. Scand J Gastroenterol 2003;38:850-5.

26. Tanaka K, Miki C, Wakuda R, Kobayashi M, Tonouchi H, Kusunoki M. Circulating level of hepatocyte growth factor as a useful tumor marker in patients with early-stage gastric carcinoma. Scand J Gastroenterol 2004;39:754-60.

27. Kodera Y, Yamamura Y, Torii A, Uesaka K, Hirai T, Yasui K, et al. The prognosis value of preoperative serum levels of CEA and CA19-9 in patients with gastric cancer. Am J Gastroenterol 1996;91:49-53.

28. Ishigami S, Natsugoe S, Hokita S, Che X, Tokuda K, Nakajo A, et al. Clinical importance of preoperative carcinoembryonic antigen and carbohydrate antigen 19-9 levels in gastric cancer. J Clin Gastroenterol 2001;32:41-4.

29. Lubin R, Zalcman G, Bouchet L, Tredaniel J, Legros Y, Cazals D, et al. Serum p53 antibodies as early markers of lung cancer. Nature Med 1995;1:701-2.

30. Zalcman G, Schlichtholz B, Tredaniel J, Urban T, Lubin R, Dubois I, et al. Monitoring of p53 auto antibodies in lung cancer during therapy: relationship to response to treatment. Clin Cancer Res 1998;4:1359-66.

31. Berloco P, Russo F, Cariola F, Gentile M, Giorgio P, Caruso ML, et al. Low presence of p53 abnormalities in H. pylori-infected gastric mucosa and in gastric adenocarcinoma. J Gastroenterol 2003;38:28-36.

32. Tan G, Xing D, Tan S, Chen Q. Rapid and sensitive immunomagnetic-electrochemiluminescent detection of p53 antibodies in human serum. J Immunol Methods 2004;288:4754. 